\title{
MULHERIO DA OUSADIA: A RESSIGNIFICAÇÃO DE CAPITU A PARTIR DAS ESTRATÉGIAS METAFICCIONAIS DE ANA MARIA MACHADO EM A AUDÁCIA DESSA MULHER
}

\author{
SANTOS, Karla Vivianne Oliveira ${ }^{1}$ \\ LOPES, Sebastião Alves Teixeira ${ }^{2}$
}

RESUMO: Em 1999, Ana Maria Machado publicou o romance A audácia dessa mulher (2011) que surgiu como uma homenagem ao escritor Machado de Assis, em comemoração ao centenário do clássico Dom Casmurro (2011). A autora se volta para o texto machadiano com uma nova mentalidade a respeito das conquistas das mulheres empreendidas a partir do século XIX e apresenta em seu texto personagens femininas audaciosas, descontentes com o papel de subserviência que a tradição patriarcal insiste em lhes reservar. Sob o viés da crítica literária, as estratégias narrativas utilizadas pela autora podem ser consideradas metaficcionais, uma vez que promovem uma autorreflexividade do texto, em que este se volta sobre si mesmo, contendo em seu bojo questionamentos ou comentários sobre o seu estatuto ficcional, narrativo, linguístico e sobre o seu processo de produção. Assim, buscamos, neste trabalho, averiguar a maneira como essas estratégias promovem a ressignificação da personagem clássica Capitu na obra de Ana Maria Machado. Para tanto, utilizamos as contribuições teóricas de Hutcheon (1991), Waugh (1984) e Faria (2012). Em nossa análise, podemos compreender melhor o papel que a personagem machadiana desempenhou no contexto do século XIX e de que maneira a autora do século XX resgata e ressignifica sua trajetória.

PALAVRAS-CHAVE: personagem feminina, ousadia, metaficção, Ana Maria Machado.

\section{WOMANHOOD OF BOLDNESS: THE RESIGNIFICATION OF CAPITU FROM THE METAFICTIONAL STRATEGIES OD ANA MARIA MACHADO IN A AUDÁCIA DESSA MULHER}

\footnotetext{
${ }^{1}$ Mestranda em Estudos Literários pelo Programa de Pós-Graduação em Letras da Universidade Federal do Piauí (PPGEL/UFPI), bolsita FAPEPI/CAPES. E-mail: viviannekarla2@ gmail.com.

${ }^{2}$ Doutor em Letras (Língua Inglesa e Literaturas Inglesa e Norte-Americana) pela Universidade de São Paulo (USP). Pós-Doutor em Teoria da Literatura pela Universidade de Londres/School of Oriental and African Studies. Professor do Programa de Pós-Graduação em Letras da Universidade Federal do Piauí (PPGEL/UFPI). E-mail: slopes10@uol.com.br.

Jangada | nr. 14, jul/dez, 2019 | ISSN 2317-4722 
ABSTRACT: In 1999, Ana Maria Machado published the novel The audacity of this woman (2011) which appeared as a tribute to the writer Machado de Assis, in celebration of the centenary of the classic Dom Casmurro (2011). The author turns to the Machado text with a new mentality regarding the achievements of women undertaken since the 19th century, and presents in her text audacious female characters, unhappy with the subservience role that the patriarchal tradition insists on reserving for them. Under the perspective of literary criticism, the narrative strategies used by the author can be considered metafictional, since they promote a self-reflexivity of the text, in which it turns on itself, containing questions or comments about its fictional, narrative status, linguistic and its production process. Thus, we seek, in this work, to investigate the way in which these strategies promote the reframing of the classic character Capitu in the work of Ana Maria Machado. For that, we used the theoretical contributions of Hutcheon (1991), Waugh (1984) and Faria (2012). In our analysis, we can better understand the role that Machado's character played in the context of the 19th century and how the 20th century author rescues and refreshes her trajectory.

KEYWORDS: female character, daring, metafiction, Ana Maria Machado.

\section{CONSIDERAÇÕES INICIAIS}

O importante reconhecimento de Ana Maria Machado se deve à vasta criação ficcional dessa autora, que trafega desde traduções e adaptações a obras infanto-juvenis e aquelas destinadas ao público adulto, que são as mais estudadas, explorando assim o universo dos livros e igualmente revelando características do projeto literário da autora. São histórias carregadas de "significados, nutridas de ambivalência e rupturas, mergulhadas no simbólico e que se cruzam no próprio ato de leitura" (PATROCÍNIO, 2014, p. 10) e, na maioria das vezes, levanta questionamentos.

A referida escritora também é reconhecida por ser uma das maiores autoras brasileiras da contemporaneidade em função da sua contribuição à literatura feminina, feita por uma mulher e para a mulher, voltando-se aos públicos infantil, juvenil ou adulto. Além disso, são frequentes em suas obras os temas da leitura e da escrita, que se expandem por meio do “emprego de múltiplos recursos linguísticos, da versatilidade literária e da humanização do leitor", pautados no respeito que a autora demonstra ter em relação ao seu público (PATROCÍNIO, 2014, p. 11). 
Um exemplo claro dessa característica da escrita de Ana Maria Machado é a obra $A$ audácia dessa mulher (2011), que surgiu em meio ao cenário literário do ano de 1999 como uma homenagem ao escritor Machado de Assis, no centenário da publicação de Dom Casmurro (2011). A referida obra é, portanto, "uma releitura e reescrita da trajetória de Capitu, que homenageia as mulheres que resolveram escrever suas próprias histórias, sem depender de um sustentáculo masculino" (FARIA, 2007, p. 128). Dessa maneira, a autora lança luz de promover uma revisão dos papéis de gênero.

Nesse sentido, o cenário das prosas modernas e contemporâneas nos faz refletir criticamente sobre seus processos de criação ficcional, levando a investigar quais elementos fazem parte do projeto literário dessas obras. No que concerne à pós-modernidade, um dos estudos que auxilia a trilhar esse caminho é o da metaficção historiográfica que, em termos gerais, apresenta uma ficção que versa sobre si própria.

Conforme Hutcheon (1991), a metaficção é o estudo do texto que reflete crítica e conscientemente sobre si mesmo, revelando novos conceitos sobre sua identidade e promovendo novas discussões acerca de um mesmo tema. Para que essa autoconsciência do texto literário aconteça, o autor deve preocupar-se em traçar estratégias narrativas que levem o leitor a desbravar os caminhos das produções ficcionais, como os recursos paródia e intertextualidade, que foram tão utilizados nas últimas décadas.

Isto posto, este trabalho propõe analisar a obra de Ana Maria Machado intitulada $A$ audácia dessa mulher (2011) por meio da produção teórica que versa sobre as estratégias da metaficção historiográfica. Buscamos, assim, compreender a maneira como a autora brasileira aplica elementos metaficcionais em sua obra, de modo a promover a ressignificação da personagem Capitu.

\section{A AUTORA, A OBRA, AS MULHERES}

A projeção do nome de Ana Maria Machado se deve ao talento dessa grande escritora da literatura brasileira, reconhecida por várias premiações em níveis nacional e internacional. Nessa conjuntura, destacam-se, por exemplo, o maior prêmio literário do Brasil (Machado de Assis, em 2001, concedido pela Academia Brasileira de Letras - ABL), e o prêmio considerado o Nobel da literatura infantil mundial (Hans Christian Andersen, em 2000, ofertado pela Internacional Board Books for Young People). 
Vemos uma vasta criação ficcional dessa autora que concentra suas produções na literatura infantil e juvenil, em romances para adultos, livros de ensaios, traduções, adaptações, além de palestras pelo Brasil e exterior. Uma marca muito forte nas obras de Ana Maria Machado, e que neste trabalho consideramos relevante, é a escolha por representar personagens femininas de todas as idades, seja individual ou coletivamente.

A exemplo disso, em A audácia dessa mulher (2011), sexta publicação ficcional voltada para o público adulto, Ana Maria Machado nos apresenta mulheres audaciosas, descontentes com o papel de subserviência que a tradição patriarcal insiste em lhes reservar. Trata-se da história de Beatriz (doravante Bia), uma jornalista de turismo, mulher independente e realizada devido aos seus objetivos e conquistas. A moça é convidada a participar da produção de uma série de TV e conhece Virgílio, um cozinheiro renomado da cidade do Rio de Janeiro.

Em meio às reuniões para a produção televisiva, os dois personagens se envolvem em um romance que, a princípio, deixa a moça confusa, já que ela possui um relacionamento complicado com o personagem Fabrício e, por isso, decidiram se manter afastados, na tentativa de reaver o compromisso e dar um novo rumo à relação.

Nesse ínterim, Virgílio e Bia se aproximam cada vez mais e ele, percebendo o interesse dela por literatura, viagens e sabores, empresta a ela um caderno de receitas que está na sua família há gerações. O rapaz acredita que esse empréstimo ajude Bia a ter mais material para a redação de seus textos. Eé a partir da leitura dessas receitas que a moça descobre, no rodapé de cada página, uma espécie de diário, escrito por alguém da família de Virgílio que passara por situações complicadas.

Imbuída da crença de que "os livros continuam uns aos outros, apesar de nosso hábito de julgá-los separadamente" (MACHADO, 2011, p. 106), Ana Maria Machado cita Virgínia Woolf para nos remontar à trajetória de Capitu, personagem de Dom Casmurro (2011), obra de Machado de Assis. A autora reinventa os caminhos percorridos por ela após sua separação de Bentinho e posterior exílio na Suíça. O argumento para a retomada da história é justamente o Cadernão da Lina - nome dado ao livro de receitas da família de Virgílio - que, depois de ter passado por várias gerações de mulheres, chega nas mãos da jornalista Bia, acompanhado de uma carta assinada por Maria Capitolina.

Lançada inicialmente em 1999, exatamente um século após a publicação de Dom Casmurro (2011), A audácia dessa mulher (2011) é uma obra escrita em homenagem ao romance de Machado de Assis, em que a autora, além de voltar-se especialmente para o texto 
machadiano, propõe um outro ponto de vista que também é possível: o olhar de Capitu sobre sua relação com Bento Santiago, dando voz à personagem feminina.

Dessa forma, neste trabalho, buscamos averiguar a maneira como as estratégias narrativas utilizadas por Ana Maria Machado em sua obra promovem a ressiginificação da personagem Capitu. Para tanto, tomaremos como base os princípios da metaficção, dos quais trataremos na seção seguinte.

\section{A METAFICÇÃO, A PARÓDIA E A INTERTEXTUALIDADE}

Desde o século XVI, no Ocidente, a História da Literatura passou a sinalizar o surgimento de um tipo de texto ficcional que é voltado para si mesmo. Esse tipo de ficção domina, em seu bojo, questionamentos ou reflexões acerca de seu estatuto linguístico, narrativo e sobre seu processo de produção e recepção. Sob essa ótica, somos levados, por um lado, a perceber com maior evidência o caráter de artefato dado a uma obra literária por meio desse tipo de ficção. Por outro lado, o modo como essas narrativas são construídas suscita comentários desenvolvidos pela crítica e/ou teoria literária, tornando-se uma forma híbrida, unindo teoria, ficção e crítica em um mesmo espaço literário.

A consciência desse hibridismo levou críticos literários a se questionarem sobre qual nome esse tipo de ficção poderia receber, tendo em vista os novos mecanismos que apresentava até então. Por essa razão, desde os últimos vinte e cinco anos do século XX, "metaficção, narrativa metaficcional, ficção ou narrativa pós moderna são os termos predominantemente utilizados para designar tais tipos de narrativas" (FARIA, 2012, p. 238). Assim, desde o século XVI e ao longo dos séculos subsequentes, o aparecimento de narrativas voltadas para si mesmas e que se autoquestionam tem sido uma constante, com ênfase em alguns períodos, como ocorreu por quase todo o século XX, na Europa e nas Américas.

Especialmente no fim do referido século, em relação às publicações dessas narrativas metaficcionais, costumou-se chamá-las de “ficções pós-modernas, tendo em vista que a metaficcionalidade, conforme teóricos da época, seria uma das marcas da pós-modernidade em literatura" (FARIA, 2012, p. 239). Essa perspectiva se contrapõe aos pressupostos de teóricos da modernidade, para quem as narrativas voltadas sobre si mesmas e que contêm questionamentos no interior da própria obra são uma marca da modernidade.

Críticas como Waugh (1984) e Hutcheon $(1989,1991)$, desde o início da década de 1980, tentam estabelecer parâmetros de análise para as obras que se integram nessa nova Jangada | nr. 14, jul/dez, 2019 | ISSN 2317-4722 
tendência pós-moderna. Waugh (1984) chama atenção para o fato de que os romances metaficcionais tendem a ser construídos com base no princípio de uma oposição fundamental: a construção e a revelação de uma ilusão fictícia. Em outros termos, a referida autora pontua que

o menor denominador comum da metaficção é simultaneamente criar uma ficção e fazer uma declaração sobre a criação dessa ficção. Os dois processos são mantidos juntos em uma tensão formal que se quebra em distinções entre 'criação' e 'crítica' e as funde nos conceitos de 'interpretação' e 'desconstrução'. (WAUGH, 1984, p. 17, tradução nossa) ${ }^{3}$

Por esse raciocínio, é comum pensar num texto metaficcional como aquele que reflete sobre si mesmo de modo crítico e consciente, tal qual aponta Hutcheon (1991) para o que realmente é destacável na metaficção: a consciência explícita da estruturação do texto literário e da relação de colaboração mútua entre autor e leitor para a construção e interpretação de uma obra. Sob esta ótica, em sua obra intitulada Poética do pós-modernismo (1991), a teórica canadense conjectura sobre as novas perspectivas do período pós-moderno, cujos questionamentos sobre ficção e história possuem muitos paradoxos.

Entretanto, Hutcheon (1991) propõe um novo conceito para a referida época, a julgar pela quantidade de mudanças e transformações que compreendem esse período. A autora o apresenta como "um empreendimento cultural e contraditório, altamente envolvido naquilo que procura contestar. Ele usa e abusa das próprias estruturas e valores que desaprova." (p. 142). Por esse excerto, a autora nos diz que o pós-modernismo dialoga com o passado da arte e da sociedade, e manifesta-se por meio da autoconsciência teórica sobre a ficção e a história como construtos linguísticos, criações humanas.

Somada a essa perspectiva, a referida autora levanta uma breve discussão em sua obra sobre a categoria do romance pós-moderno, pontuando que ele "faz parte da postura pósmodernista de afrontar os paradoxos da representação fictícia/histórica, do particular/geral e do presente/passado" (HUTCHEON, 1991, p. 142). Dessa forma, as produções desses romances reinserem contextos históricos significativos e determinantes mas, ao fazê-los, problematizam toda a noção de conhecimento histórico.

\footnotetext{
${ }^{3}$ Do original: “(...) the lowest common denominator of metafiction is simultaneously to create a fiction and to make a statement about the creation of that fiction. The two processes are held together in a formal tension which breaks down the distinctions between 'creation' and 'criticism' and merges them into the concepts of 'interpretation' and 'deconstruction'” (WAUGH, 1984, p. 17).
} 
É sob esse viés que a metaficção historiográfica se mantém, quando o texto reflete consciente e criticamente sobre si mesmo, revelando novos conceitos da sua identidade e possibilitando novas discussões acerca de um mesmo tema. Consoante a isso, segundo Hutcheon (1991), a metaficção

refuta os métodos naturais, ou de senso comum, para distinguir entre o fato histórico e a ficção. Ela recusa a visão de que apenas a história tem uma pretensão à verdade, por meio do questionamento da base dessa pretensão na historiografia e por meio da afirmação de que tanto a história como a ficção são discursos, construtos humanos, sistemas de significação, e é a partir dessa identidade que as duas obtêm sua principal pretensão à verdade. (HUTCHEON, 1991, p. 127)

Por esses termos, compreendemos que a função do fato histórico numa obra literária vai além de uma simples inserção de contextos históricos. Ao contrário, é a partir dessa contextualização histórica que ocorre a problematização do conhecimento histórico, tendo em vista que a abordagem desse passado é feita por meio da textualidade, desencadeando um conflito entre realidade e ficção, ambas questionadas pela metaficção historiográfica.

Partindo desse pressuposto, Hutcheon (1991) considera que a problematização gerada pela metaficção acontece por meio desses questionamentos sobre realidade e ficção, que são desencadeados por estratégias narrativas utilizadas para a construção dos textos literários. Assim, a autora canadense propõe três estratégias que ela concorda serem cruciais para a tessitura de obras metaficcionais: paródia, intertextualidade e discursos da história. Para a análise feita neste trabalho, tomamos como base apenas os conceitos difundidos por Hutcheon (1991) acerca da intertextualidade e da paródia.

Em sua obra intitulada A poética do pós-modernismo (1991), Linda Hutcheon define a paródia como sendo o método que o fazer literário do pós-modernismo achou de voltar ao passado fazendo um retrospecto e, também, retratando o múltiplo, o heterogêneo e o diferente, assumindo uma forma intertextual e paradoxal que, conforme a referida autora, "configura-se como uma transgressão autorizada" (1991, p. 95).

A paródia se revela, portanto, como uma das características fundamentais da escrita metaficcional porque incorpora e desafia o objeto parodiado, obrigando a si mesma a ter autenticidade. O recurso da paródia não só realiza um diálogo entre o passado e o presente, 
como também uma repetição com distância crítica por meio da ironia, podendo ocasionar tanto uma mudança quanto uma continuidade de seus estudos. Dessa maneira, a paródia intertextual da metaficção historiográfica encena uma opinião: “ela apresenta uma sensação de presença do passado, mas de um passado que só pode ser conhecido através de seus textos, de seus vestígios - sejam eles literários ou históricos" (HUTCHEON, 1991, p. 164).

Em Uma teoria da paródia (1989), Linda Hutcheon sugere que o homem pós-moderno tem a necessidade de afirmar o seu lugar na tradição cultural que o cerca e, por isso, é levado a buscar a incorporação do velho com o novo, "num processo de desconstrução e reconstrução por meio dos recursos estilísticos presentes na ironia e na inversão" (p. 54). Partindo desse pressuposto, a paródia não se destacaria apenas pelo seu potencial de subverter e de ridicularizar, pois, conforme Hutcheon (1989), a paródia é "repetição, mas repetição que inclui diferença; é imitação com distância crítica, cuja ironia pode beneficiar e prejudicar ao mesmo tempo. Versões irônicas de 'transcontextualização' e inversão são [seus] principais operadores formais $[\ldots] "$ (p. 54).

Por esse pensamento, a crítica canadense pontua que, em tempos de pós-modernidade, a paródia se tornou a própria via predominante da criação artística. A sua "inversão irônica é seu novo modo de operar, mas a sua essência reside na possibilidade de autorreflexão" (HUTCHEON, 1989, p. 13), na busca pelo distanciamento crítico e do diálogo inerente com a obra de arte, seja na literatura ou em qualquer outro modo de expressão da arte.

Além da paródia, outro recurso metaficcional do qual Hutcheon (1991) apodera-se para tratar da metaficção historiográfica é a intertextualidade. Em sua obra, Poética do pósmodernismo (1991), a autora canadense chama atenção para a ideia de que existe um retorno à noção de uma "propriedade" discursiva comum entre os textos literários e históricos dentro da ficção. Todavia, esse é um retorno, conforme a autora, problematizado por "questões metaficcionais sobre a história e a literatura como construtos humanos” (p. 164).

Tomando como base os estudos de pesquisadores como Julia Kristeva e Mikhail Bakhtin acerca das teorias sobre os discursos e vozes do texto, Hutcheon (1991) toma emprestado o termo intertextualidade para tratar sobre as várias referências que um texto literário pode conter. A teórica canadense assevera que os textos podem ser referenciados de várias maneiras, seja pela paródia, pastiche, alusão, citação etc. Entretanto, é a intertextualidade a condição primeira da literatura. Segundo Hutcheon (1991), “a intertextualidade é um 
entrelaçamento de vozes que proporciona ao leitor conhecer os detalhes de uma obra, bem como sua constituição, posto que anteriormente isto não havia sido permitido" (p. 166).

A partir disso, é possível visualizar o nascimento de múltiplas ideias a partir de um único texto e que, conforme Hutcheon (1991), “a incorporação textual desses passados intertextuais como elemento estrutural constitutivo da ficção pós-modernista funciona como uma marcação formal da historicidade tanto literária quanto mundana" (p. 163). Sob esse raciocínio, a pesquisadora canadense nos mostra que a intertextualidade permite que o leitor visualize, na metaficção, não apenas o reconhecimento de vestígios textualizados do passado literário e histórico.

De acordo com a autora, esse tipo de ficção pós-moderna proporciona ao leitor, principalmente, a percepção daquilo que fora feito desses vestígios. De acordo com essa ótica, Hutcheon (1991) toma como exemplo palavras do escritor italiano Umberto Eco que, ao escrever sobre um de seus romances, assegura: "Descobri o que os escritores sempre souberam (e nos disseram muitas vezes): os livros sempre falam sobre outros livros, e toda a história conta uma história que já foi contada" (ECO, 1983 apud HUTCHEON, 1991, p. 167).

Dadas as considerações acerca da metaficção historiográfica e de suas estratégias narrativas de produção, passaremos a ver, na seção seguinte, a maneira como as referidas estratégias promovem a ressignificação da personagem Capitu em A audácia dessa mulher (2011), obra de Ana Maria Machado.

\section{A RESSIGNIFICAÇÃO DE CAPITU A PARTIR DE ESTRATÉGIAS METAFICCIONAIS}

A julgar pela variedade de livros publicados para os públicos infantil e juvenil, o nome de Ana Maria Machado sempre se manteve em evidência entre os maiores expoentes dessa vertente literária no Brasil. É fato que também se destaca em meio aos nomes de escritores que dedicaram-se à contar histórias para o público adulto. Percebemos, em nossas leituras, que uma de suas características mais singulares é a escolha por representar personagens femininas de todas as idades, seja de maneira individual ou coletiva.

Em A audácia dessa mulher (2011), obra em análise neste trabalho, voltamos nossa atenção para o modo como Ana Maria Machado reinventa e ressignifica a trajetória de Capitu, imortalizada no clássico Dom Casmurro (2011), de Machado de Assis, um século antes. Essa personagem reinventada pela escritora carioca surge em meio à teia narrativa que se desenvolve 
em torno da trajetória de Beatriz, uma jornalista de sucesso ambientada no finalzinho do século $\mathrm{XX}$, cujas mãos chegam em alguns textos que supostamente foram escritos por Capitu.

Tendo como base os pressupostos teóricos da metaficção historiográfica, que versam sobre o recurso da paródia como estratégia narrativa, percebemos que ela se refere a uma espécie de repetição que se baseia na diferença, ou numa imitação que pressupõe distância crítica, cuja ironia pode tanto ser benéfica quanto prejudicial à tessitura do texto ficcional. Dessa forma, podemos identificar, na obra de Ana Maria Machado (2011), que o texto parodiado pela autora é o clássico machadiano, como vemos no trecho a seguir:

Geralmente, B., que faz o padre, é quem traz o doce. Mas quando há sequilhos em casa, levo eu alguns ao quintal para nossas brincadeiras. Desmanchamse na boca. Uma delícia! Menos, porém, que o beijo que trocamos outro dia após o penteado. Uma vertigem! E eu a pensar que esgotara todas as sensações de deleite minutos antes, enquanto ele me fazia as tranças, tocava minha nuca, roçava seus dedos por minhas costas, devagar, devagarinho... Felizmente, tive o súbito impulso de atrair sua boca à minha. Um estremeção que nos deixou sem fala. Por pouco minha mãe não nos surpreende. (MACHADO, 2011, p. 59, grifos da autora)

O excerto faz menção ao episódio em que Bentinho está fazendo tranças nos cabelos de Capitu e ela surpreende-o com um beijo, momento em que o rapaz se vê, por alguns segundos, sem saber como agir: "Grande foi a sensação (...) eu recuei até a parede com uma espécie de vertigem, sem fala, os olhos escuros" (ASSIS, 2011, p. 67). O uso da paródia na obra de Ana Maria Machado (2011) permite ao leitor visualizar o encontro de duas personagens (Beatriz e Capitu) que muito se assemelham em seus comportamentos e modos de pensar, e separadas há exatamente um século, fato que nos possibilita perceber a homenagem feita pela escritora carioca a Machado de Assis.

Por esse raciocínio, a inquirição do processo narrativo de Machado (2011) deriva das lacunas deixadas pelo texto homenageado, já que Capitu é silenciada e exilada pelo marido na Suíça, onde morre sozinha, anos mais tarde, em razão de tê-lo "traído" com o melhor amigo, sem que qualquer chance de defesa lhe tenha sido dada. Em A audácia dessa mulher (2011), a autora nos apresenta uma nova versão para a história do casal machadiano, agora sob a perspectiva da personagem feminina. 
A obra de Machado (2011), no entanto, nos propõe analisar teorias de obras romanescas que "subvertem as convenções do gênero (romance)" (FARIA, 2012, p. 242) exatamente porque suscita questionamentos sobre si mesma, a julgar pelos detalhes com os quais a autora tratou de escrever o Cadernão da Lina, em referência à existência da personagem Capitu, até então muito discutida desde a publicação de Dom Casmurro (2011). Assim, além da paródia, também foi possível analisarmos o texto da escritora carioca por meio do recurso narrativo da intertextualidade.

Uma vez que, tal qual disse Umberto Eco (1983) em que os textos sempre falam de outros textos, consideramos a intertextualidade uma condição da textualidade, já que o diálogo entre textos provoca e revela o real valor do texto ficcional e do conhecimento que o leitor pode adquirir por meio da leitura de uma obra de ficção. Sob esses aspectos, em A audácia dessa mulher (2011), Ana Maria Machado toma como exemplo outros autores da Literatura e das Ciências Humanas para a construção de seu romance.

Um exemplo disso é quando cita Karl Marx e, em seguida, quando relembra Virgínia Woolf:

Vale ainda lembrar que, embora não seja o caso de precisar exatamente em que ano, o fato é que bem nesse momento (...) lá do outro lado do Atlântico um judeu barbudo voltava seu olhar e sua inteligência para a sociedade europeia da época (...). Não é exagero dizer que (...) Karl Marx iria revolucionar o mundo. (MACHADO, 2011, p. 52-53)

De onde vinha a vontade de aprender? Um absurdo fazer uma pergunta dessas. Sabia dentro de si de onde vinha e era a mesma que a movia. (...) Parenta do eterno fascínio pelo conhecimento dos clássicos negado às mulheres, que Virginia Woolf mencionara tantas vezes, suspirando por estudar grego. (MACHADO, 2011, p. 58)

Pelos trechos citados anteriormente, percebemos que o texto de Machado (2011) nos permite visualizar não apenas o reconhecimento de vestígios (históricos ou ficcionais) textualizados, como também ocasiona a percepção daquilo que foi feito deles (HUTCHEON, 1991). Nesse sentido, enquanto recurso da narrativa pós-moderna, a intertextualidade faz parte de uma "escrita fictícia que conscientemente e sistematicamente chama a atenção para seu 
status de artefato, a fim de colocar questões sobre a relação entre ficção e realidade" (WAUGH, 1984, p. 13, tradução nossa ${ }^{4}$ ).

Pautados sob esse caminho da autorreflexividade, vejamos o excerto a seguir:

Aos outros [leitores], (...) agradeço a companhia e faço um convite. Venham comigo ler a carta de Lina e mergulhar com Bia no que ela encontrar, nessas águas moventes onde se cruzam ficção e realidade, no contínuo fluxo de livros que se esparramam por nossa vida e a fecundam.

Vevey, 28 de março de 1911.

Minha querida amiga Sancha,

Bem imagino tua incredulidade ao receber esta carta. Seguramente me tens por morta e enterrada há mais de vinte anos. (...) (MACHADO, 2011, p. 105, grifos da autora)

O trecho da obra de Machado (2011) lança mão de apresentar aos seus leitores a carta que, segundo a autora, foi escrita por Maria Capitolina nas últimas páginas do caderno de receitas/diário lido pela personagem Beatriz. O excerto encontra-se em um dos últimos capítulos da obra analisada, e por meio dele podemos identificar o mecanismo da referência, característica básica da intertextualidade enquanto recurso metaficcional.

Como vemos, a estratégia de Machado (2011) consiste em promover o encontro entre Capitu e Beatriz: uma personagem de ficção sendo apresentada à outra como se, de fato, esse momento fizesse parte da realidade, acontecendo um século após a publicação do clássico machadiano. A respeito dessa atitude crítica empregada pela escritora carioca, percebemos que sua intenção era dar continuidade ao livro homenageado. Seguindo essa linha de pensamento, a pesquisadora Zolin (2005) comenta que é conforme esse espírito de dar prosseguimento às narrativas de outros tempos que "os caminhos que teriam sido trilhados por Capitu (...) são iluminados. Tudo o que não foi dado ao leitor do romance original saber sobre essa intrigante personagem feminina, a quem Machado não deu voz, (...) é permitido conhecer agora" (2005, p. 1292).

Consoante a isso, as estratégias metaficcionais nas quais nos apoiamos para realizar a análise feita neste trabalho foram cunhadas por Hutcheon (1991), que apontou para as novas estruturas dos textos ficcionais do período pós-moderno. Por outro lado, cuidando em frisar abertamente sobre o caráter puramente crítico da metaficção, Waugh (1984) nos diz que "ao

\footnotetext{
${ }^{4}$ Do original: “(...) fictional writing which self-consciously and systematically draws attention to its status as an artefact in order to pose questions about the relationship between fiction and reality" (WAUGH, 1984, p. 13).
} 
fornecer uma crítica de seus próprios métodos de construção, esses escritos não apenas examinam as estruturas fundamentais da ficção narrativa, mas também exploram a possível ficcionalidade do mundo fora do texto ficcional literário" (WAUGH, 1984, p. 13, tradução nossa $\left.a^{5}\right)$.

Em meio a discussões acerca dos diversificados textos que compõem o romance de Ana Maria Machado (2011), entendemos, portanto, que a orientação dos pressupostos teóricos da metaficção historiográfica dada a esta análise, nos permitiu alcançar o objetivo geral proposto neste trabalho. Dessa forma, revelou-se, a partir desta pesquisa, um novo viés para $A$ audácia dessa mulher (2011), em que identificamos como a intertextualidade e a paródia promoveram a ressignificação da personagem machadiana Capitu.

\section{CONSIDERAÇÕES FINAIS}

Em nossa análise, buscamos compreender a maneira como a autora do século XX, Ana Maria Machado, resgata e ressignifica a trajetória da personagem machadiana no contexto do século XIX, Capitu, por meio dos mecanismos narrativos elencados pelos pressupostos teóricos da metaficção historiográfica.

Diante do exposto em nosso trabalho, identificamos que a escrita da obra de Ana Maria Machado se constitui de discursos ficcionais que permitem ao leitor visualizar outro ponto de vista da história contada por Machado de Assis em Dom Casmurro (2011). Mais ainda: a escritora retoma a trajetória de Capitu, (re)criando-lhe contornos, (re)inventando-lhe os caminhos percorridos durante o tempo em que esteve casada com Bentinho.

A paródia e a intertextualidade, estratégias narrativas metaficcionais utilizadas para a tessitura do romance, nos permitem ressignificar Capitu, ambientada no século XIX e reconhecida por uma personagem feminina situada no fim do século XX. Ana Maria Machado nos mostra a ousadia de Capitu e suas personagens femininas em A audácia dessa mulher (2011), todas a frente de seu tempo e donas de suas histórias. Acreditamos, portanto, termos acrescentado uma nova abordagem à maneira como a referida obra vem sendo analisada, contribuindo, assim, para ampliar o universo de estudos críticos sobre a totalidade da obra de Ana Maria Machado.

\footnotetext{
${ }^{5}$ Do original: "In providing a critique of their own methods of construction, such writings not only examine the fundamental structures of narrative fiction, they also explore the possible fictionality of the world outside the literary fictional text" (WAUGH, 1984, p. 13).
} 


\section{REFERÊNCIAS BIBLIOGRÁFICAS}

ASSIS, Machado de. Dom Casmurro. São Paulo: Orbis Editora. 2011.

FARIA, Zênia de. A metaficção revisitada: uma introdução. Signótica, v. 24, n. 1, p. 237-251, jan./jun. 2012

FARIAS, L. W. B. A audácia dessa mulher: Ana Maria Machado e a subversão do cânone na reescrita de Capitu. 2007. 236 p. Dissertação (Mestrado em Letras). Universidade Estadual de Maringá, Maringá, 2007.

HUTCHEON, Linda. Poética do pós-modernismo: história, teoria, ficção. Tradução: Ricardo Cruz. Rio de Janeiro: Imago Ed.,1991.

HUTCHEON, Linda. Uma teoria da paródia. Lisboa: Edições 70, 1989.

MACHADO, Ana Maria. A audácia dessa mulher. $3^{\text {a }}$ Edição. Rio de Janeiro: Objetiva, 2011. PATROCÍNIO, Gabriela T. G. Ana Maria Machado: da criação ficcional à crítica - O valor da leitura literária. 2014. 106 p. Dissertação (Mestrado em Letras). Pontifícia Universidade Católica de São Paulo (PUC-SP), São Paulo, 2014.

WAUGH, Patricia. Metafiction: the theory and practice of self-conscious fiction. London; New York: Routledge, 1984.

ZOLIN, Lúcia O. A personagem feminina na literatura brasileira escrita por mulheres: de objeto a sujeito. In: XI SEMINÁRIO INTERNACIONAL MULHER E LITERATURA. II SEMINÁRIO INTERNACIONAL MULHER E LITERATURA. Anais. Rio de Janeiro, UERJ, 2005, p. 1291-1302. 